\title{
FORMAÇÃO DE PROFESSORES E PROFISSÃO DOCENTE: $O$ ESTADO DO CONHECIMENTO DA PESQUISA EM FORMAÇÃO NA REGIÃO DOS INCONFIDENTES - MG
}

\author{
José Rubens Lima Jardilino ${ }^{1}$, Andressa Maris Rezende Oliveri ${ }^{2}$, Ana Maria Mendes Sampaio ${ }^{3}$ \\ ${ }^{1}$ Doutorado em Ciências Sociais pela Pontifícia Universidade Católica de São Paulo - PUC, SP. Professor da \\ Universidade Federal de Ouro Preto - UFOP, Departamento de Educação - DEEDU e do Programa de Pós-Graduação \\ em Educação - PPGE-UFOP. ORCID iD: https://orcid.org/0000-0003-2394-9465. E-mail: jrjardilino@ufop.edu.br. \\ ${ }^{2}$ Doutoranda em Educação pelo Programa de Pós-Graduação em Educação da Universidade Federal de Ouro Preto - \\ PPGE-UFOP. ORCID iD: https://orcid.org/0000-0001-9135-6296. E-mail: andressamaris@yahoo.com.br \\ ${ }^{3}$ Doutoranda em Educação pelo Programa de Pós-Graduação em Educação da Universidade Federal de Ouro Preto - \\ PPGE-UFOP. ORCID iD: https://orcid.org/0000-0002-9821-911X. E-mail: anamendessampaio@yahoo.com
}

\section{RESUMO}

O campo educacional insere-se em um contexto de múltiplos atores, ações e implicação social, sendo necessário o uso de várias lentes para que se possa compreender seu movimento. Em virtude disso, este trabalho tem como objetivo rememorar parte da trajetória de formação e pesquisa do Grupo de Pesquisa Formação e Profissão Docente (FOPROFI), do Programa de Pós-Graduação em Educação da Universidade Federal de Ouro Preto. Para isso, serão demonstradas algumas das pesquisas desenvolvidas pelo grupo que auxiliaram na composição e conhecimento dos campos - formação de professores, profissão docente e instituições escolares. As pesquisas foram selecionadas a partir do levantamento destes trabalhos no repositório da universidade. Buscou-se traçar algumas considerações a respeito destes campos e sua interseção na experiência de formação e desenvolvimento profissional na Região dos Inconfidentes e seu impacto social na compreensão dos desafios educacionais. Compreendemos que as ações organizadas pelos grupos de pesquisa extrapolam as fronteiras da pesquisa por meio da formação e inserção social dos sujeitos-professores e alunos na sociedade. Por isso, é importante a promoção da formação a partir das redes de pesquisa, sejam elas articuladas com outras instituições de ensino ou dentro do próprio grupo de pesquisa, colaborando para melhoria da educação no âmbito regional e nacional.

Palavras-chave: Formação de Professores. Profissão Docente. Instituições Escolares. Pesquisa em rede.

\section{TEACHER EDUCATION AND TEACHING PROFESSION: THE STATE OF KNOWLEDGE OF RESEARCH IN TRAINING IN THE REGION OF INCONFIDENTES -MG}

\section{ABSTRACT}

The educational field is inserted in a context of multiple actors, actions, and social implications, requiring the use of several viewpoints to understand its movement. As a result, this work aims to remember part of the training path and research trajectory of the Research Group -Teacher Education and Profession (FOPROFI), of the Graduate Program in Education of the Federal University of Ouro Preto. In order to do so, some of the research developed by the group that helps in the composition and knowledge of the field of teacher education, in the teaching occupation and in educational institutions will be treated. The researches were selected after the bibliographic survey of the works in the university repository. In addition, we sought to outline some considerations regarding these fields and their intersection in the experience of training and professional development in the Region of Inconfidentes and their social impact in understanding educational challenges. We understand that the actions organized by the research groups go beyond the frontiers of research through the formation and social insertion of subjects- teacher and studentin society. For this reason, it is important to promote education through in Networks Research, whether they are articulated with other educational institutions or within the research group itself, collaborating to improve education at regional and national levels. 
Keywords: Teacher education, Teaching profession. School institutions. Network research.

\section{FORMACIÓN DEL MAESTRO Y PROFESIÓN DOCENTE: EL ESTADO DEL CONOCIMIENTO EN LA FORMACIÓN EN LA REGIÓN DE LOS INCONFIDENTES, MG}

\section{RESUMEN}

El campo educativo se inserta em un contexto de múltiples actores, acciones e implicaciones sociales, requiriendo el uso de varios puntos de vista para comprender su movimiento. El objectivo central del trabajo es recordar parte de la trayectoria formativa y trayectoria investigativa del Grupo de Investigación en Formación y Profesión Docente (FOPROFI), del Programa de Posgrado en Educación de la Universidad Federal de Ouro Preto. Para tal, se desmonstrarán algunas de las investigaciones desarrolladas por el grupo que ayudó en la composición y conocimiento del campo de la formación del profesorado, en la profesión docente $y$ en las instituciones educativas. Las investigaciones fueron seleccionadas tras el recogido bibliográfico de los trabajos en el repositorio de la universidad. Además, buscamos esbozar algunas consideraciones sobre estos campos y su intersección en la experiencia de formación y desarrollo profesional en la Región de los Inconfidentes y su impacto social en la comprensión de los desafíos educativos. Entendemos que las acciones organizadas por los grupos de investigación trascienden las fronteras de la investigación a través de laformación e inserción social de los sujetos maestros y estudiantes en la sociedad. Por eso, es importante promover la educación a través de redes de investigación, sean estas articuladas con otras instituciones educativas o dentro del propio grupo de investigación, colaborando para mejorar la educación a nivel regional y nacional.

Palabra-clave: Formación de Maestro, Profesión Docente, Instituciones Educativas, Red de Investigación

\section{INTRODUÇÃO}

A temática da formação de professores é uma pauta de discussão, seja no meio social ou acadêmico. Na história da educação no Brasil temos esta discussão desde muito cedo, quando ainda no Império, as assembleias provinciais debatiam a necessidade de formar professores para a educação dos filhos da pátria (PEDRUZZI, JARDILINO, 2016; TANURI, 2000; VILELLA, 1990). Nessa trajetória histórica e de acordo com as políticas implementadas à cada época no Brasil para a formação de professores, chegamos a nossa contemporaneidade, de modo geral, com o legado de atribuir ao professor, o fracasso ou sucesso da educação. Entretanto, sabemos que uma educação de qualidade pressupõe diversos fatores que vão além de indicadores educacionais, tais como políticas públicas de indução e financiamento da educação, condições de trabalho dos docentes e outros profissionais da educação, salários, formação para atuação nos diferentes espaços escolares e não escolares, dentre outros.

Todos esses aspectos acima apontados contribuem para as mais variadas visões da escola, do ensino e da formação em cada momento histórico. É imprescindível o uso de várias lentes para que se possam apreender seus múltiplos atores, ações e a implicação social das ações formativas no processo educacional.

Em virtude disso, este trabalho tem como objetivo reunir parte da trajetória de formação e pesquisa do Grupo de Pesquisa Formação e Profissão Docente, do Programa de PósGraduação em Educação da Universidade Federal de Ouro Preto, a partir de um levantamento das pesquisas desenvolvidas pelo grupo, as quais ajudaram sobremaneira na composição e conhecimento do campo da formação de professores, profissão docente e das instituições escolares na Região dos Inconfidentes ${ }^{1}$, MG nos últimos 10 anos.

O texto organiza-se do seguinte modo: a primeira parte trata de aspectos históricos da constituição do grupo e a apresentação das linhas de pesquisa. A segunda versará sobre os eixos de pesquisa, os projetos de trabalho e seus reflexos nas produções que compõem o mosaico de

\footnotetext{
${ }^{1}$ A designação de uma "microrregião dos Inconfidentes" refere-se a uma localização histórica, mais do que a uma divisão geopolítica de Minas Gerais. No mapa político do Instituto Brasileiro de Geografia e Estatística (IBGE), ela é designada como a microrregião de Ouro Preto, pertencente à mesorregião Metropolitana de Belo Horizonte. O Grupo Foprofi vem utilizando o termo 'Inconfidentes' em suas pesquisas como referência espaço-temporal, histórica e política para demarcar territorialmente o campo, sendo Minas Gerais o lócus de nossa atuação. Essa região compreende os municípios de Acaiaca, Diogo de Vasconcelos, Itabirito, Ouro Preto, Mariana.
} 
formação e profissão docente na região. E, por fim, apresentamos algumas considerações sobre a interseção destes nos campos da formação de professores e instituições escolares.

A construção da memória de grupos de pesquisa colabora para a compreensão da trajetória do campo de formação docente, dos impactos sociais das ações formativas em parceria com instituições escolares e outras instâncias sociais. Além de propiciar o planejamento de novos caminhos que podem ser percorridos no processo de formação dos sujeitos que atuam no campo educacional.

O campo da formação de professores contempla várias perspectivas, pois cada nível e modalidade de ensino apresenta suas especificidades. Entre estas se destacam a atuação na sala de aula, as práticas pedagógicas, a constituição do ser professor, as condições de trabalho e carreira, a profissionalidade, além da história das instituições e dos sujeitos que fazem e fizeram parte destas.

Vários trabalhos de pesquisa foram realizados com $o$ intuito de compreender 0 desenvolvimento das temáticas de pesquisa e a configuração do campo conforme compreendem André (2010), Jardilino et al. (2011), Romanowski (2012), Cunha (2013). Desta forma, como aponta Cunha (2013), as tendências e concepções de formação docente incidem nas temáticas das pesquisas, influenciando as políticas, a constituição da profissão e dos sujeitos envolvidos nesta.

É possível identificar, no movimento de constituição do campo de pesquisa de formação de professores, distintas concepções acerca do professor: como técnico e aplicador do saber ou como um pesquisador do contexto escolar e, nesse sentido, como alguém que exerce uma prática reflexiva. Essas concepções destacam a centralidade do papel político do docente para a promoção da realidade social.

As tendências no campo da formação docente revelam a preocupação com a dimensão holística do profissional, de sua pessoa e da escola, o desenvolvimento de saberes e conhecimentos que unam teoria e prática, além de pensar na formação das futuras gerações em uma sociedade que está em constante transformação e em busca de novos desafios e experiências.

O Grupo de Pesquisa Formação e Profissão Docente (FOPROFI/UFOP) insere-se neste contexto de tendências e perspectivas de formação, ao ser constituído no ano de 2011, sob a coordenação dos professores Dr. José Rubens Lima Jardilino, Dra. Célia Maria Fernandes Nunes abrigados no Programa de Pós-Graduação em Educação da Universidade Federal de Ouro Preto, no Instituto de Ciências Humanas e Sociais (ICHS), na cidade de Mariana em Minas Gerais.

A sua criação ocorre a partir da necessidade de acolher pesquisas e pesquisadores que já desenvolviam trabalhos sobre Formação de Professores no Departamento de Educação da UFOP (DEDEU-UFOP) e estavam ligados a outros grupos de pesquisa como o Núcleo de Estudos e Pesquisa sobre as Licenciaturas (NEPEL) e o Núcleo de Estudo sobre a Sociedade, Família e Escola (NESFE). Naquele momento não havia nenhum grupo na universidade que tivesse sua atenção voltada especificamente para as questões da formação, profissão, trabalho docente e instituições formadoras de professores na região.

A criação do curso de Pedagogia em 2008 e do PPG de Educação, com a primeira turma iniciada em 2011, acontece no contexto de implementação do Programa de Apoio a Planos de Reestruturação e Expansão das Universidades Federais (Reuni), iniciado em 2007, portanto, coincide com o processo de expansão e criação de cursos na universidade. Além disso, os vários projetos em andamento pela equipe demonstraram um amadurecimento temático no Departamento de Educação, fato que também justifica a criação do grupo. O FOPROFI surge em meio a esse momento de ampliação e reestruturação da educação pública, o que demonstra que as temáticas de pesquisa do grupo se ajustam às demandas institucionais, regionais e nacionais de pesquisa.

No ano de 2012, o grupo já se encontrava cadastrado no Diretório dos Grupos de Pesquisa no Brasil e iniciava uma parceria, advinda de relações acadêmicas anteriores do líder do grupo Prof. Dr. José Rubens Lima Jardilino, com o Historia de la Universidad Latino americana HISULA. Em 2014, o FOPROFI organizou o "Seminário Regional de Pesquisa sobre Formação e Profissão Docente", com o tema: "O que dizem as pesquisas sobre formação e profissão docente", o qual congregou pesquisadores de diversas universidades e regiões do estado de Minas Gerais.

Com relação à dimensão e a composição do grupo, no ano de 2012, o FOPROFI contava com pesquisadores(as) universitários(as), 
alunos(as) da graduação/iniciação científica (IC), mestrandos(as) e colaboradores(as) internacionais, como podemos ver no gráfico $1 \mathrm{a}$ seguir:

Gráfico 1. Composição FOPROFI/UFOP - 2012

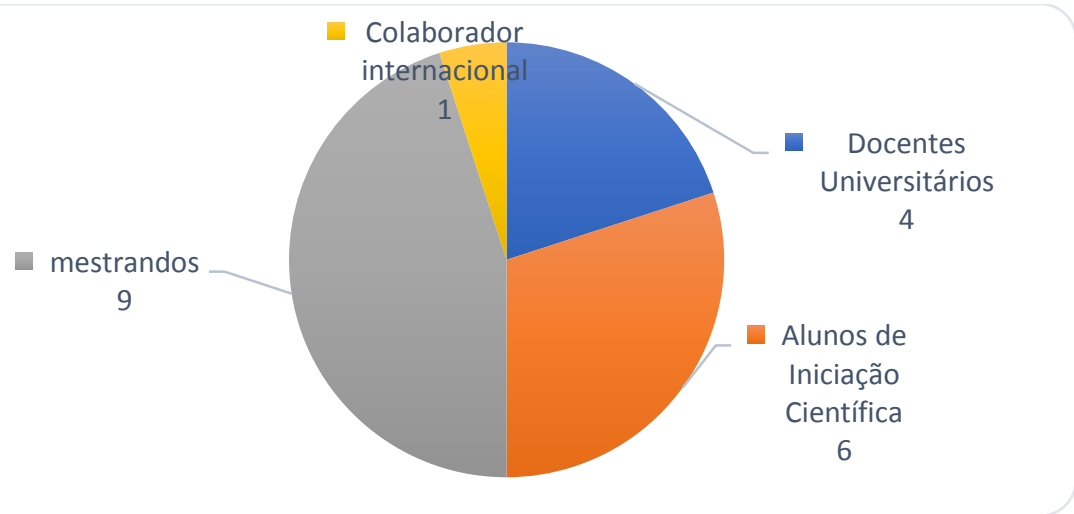

Fonte: Os autores

Nota: Organizado a partir do levantamento da produção do FOPROFI.

Atualmente, ele congrega pesquisadores, alunos de graduação/iniciação científica e pósgraduação (mestrado e doutorado) da própria instituição e de outras instituições de ensino, profissionais da educação básica, além das redes de pesquisa Capes/OBEDUC; Pensar a Educação Pensar o Brasil/UFMG; Rudecolombia - Rede Universidades publicas colombianas. O FOPROFI mantém parceria com o grupo Historia de La Universidad Latinoamericana - HISULA, com sede na Colômbia, na Universidad Pedagógica y
Tecnológica da Colômbia. E realizou uma nova parceria com o Colégio das Américas na Universidade Pablo de Olavide, Sevilha, Espanha, contribuindo, assim, para o desenvolvimento de projetos de pesquisa e formação em âmbito internacional. $\mathrm{O}$ gráfico 2 apresenta a composição e dimensão do grupo do ano de 2019, conforme vemos a seguir;

Gráfico2. Composição - FOPROFI/UFOP - 2019

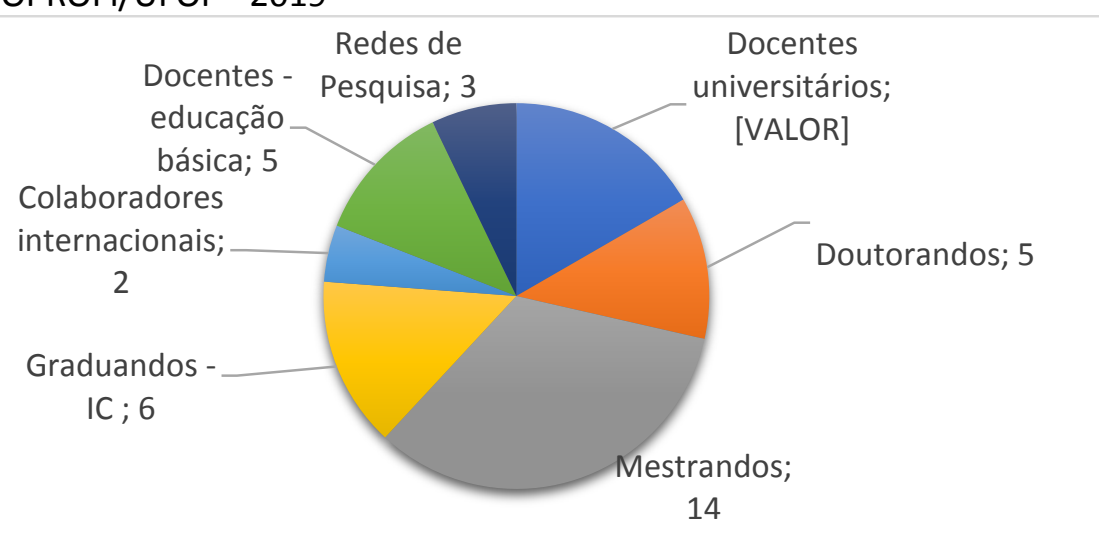

Fonte: Os autores

Nota: Organizado a partir do levantamento da produção do FOPROFI.

Assim, o FOPROFI, ao longo de sua trajetória, vem consolidando seu grupo de trabalho e estreitando laços por meio de parcerias com outras instituições de ensino superior e outros grupos de pesquisa. As parcerias e as redes de pesquisa contribuem para o fortalecimento da formação dos professores da região, os quais têm participado das discussões sobre este tema nos espaços da universidade, da escola e da gestão municipal. 
Já as suas pesquisas têm um olhar voltado para a compreensão da realidade da educação e da formação dos profissionais na Região dos Inconfidentes - MG, que circunscreve os municípios pertencentes a 25a Superintendência Regional de Ensino de Minas Gerais, a qual pertencem os municípios de Acaiaca, Diogo de Vasconcelos, Itabirito, Mariana e Ouro Preto. Pesquisadores seniores das Instituições de Ensino Superior (IES) envolvidas, alunos de Iniciação Científica, estudantes de Mestrado e Doutorado e docentes da Rede Pública Municipal e Estadual da região e colegas do HISULA convivem em um espaço de fomento e reflexão. A observação e investigação permitem a partilha de conhecimentos, saberes e experiências, respeitando os tempos e momentos de aprendizagem coletiva e individual.

As pesquisas desenvolvidas neste grupo estão em consonância com a Linha de pesquisa "Formação de Professores, Instituições e História da Educação" do Programa de Pós-Graduação em Educação da UFOP, cujo foco é a investigação no campo da formação e profissão docente, as instituições escolares, história da educação brasileira, a gestão educacional e as políticas públicas de educação. Além disso, o grupo promove o constante diálogo entre graduação e pós-graduação, contribuindo para a formação dos estudantes de modo interdisciplinar, com o desenvolvimento de projetos de pesquisas, dos quais originam trabalhos de iniciação científica, teses e dissertações.

\section{OS EIXOS DE PESQUISA E A PRODUÇÃO ACADÊMICA DO FOPROFI}

Para rememoração das temáticas, eixos de pesquisa e as produções acadêmicas relacionadas ao campo da formação docente, foi realizado um levantamento dos projetos de pesquisas e produções acadêmicas desenvolvidas pelo grupo. Desta forma, este trabalho tem o intuito de colaborar para a compreensão do campo da formação, profissão docente e das instituições escolares e para a formação de pesquisadores no espaço da escola e da universidade mediante a congregação das atividades do grupo de pesquisa. E, contribuir para os estudos sobre a configuração do campo da formação e profissão docente por meio da formação pela pesquisa.

Vários trabalhos foram desenvolvidos em conjunto pelo grupo, como também pesquisas de iniciação científica, mestrado e, atualmente, doutorado, iniciado no ano de 2019. Para este momento, selecionamos algumas pesquisas e trabalhos que foram desenvolvidos em parceria, e a produção acadêmica dos integrantes do grupo.

Os eixos de pesquisa do FOPROFI estão organizados de acordo com as seguintes temáticas: a) formação inicial, continuada, desenvolvimento profissional; b) saberes, práticas e inovação pedagógica, c) profissão, condição e carreira; d) processos de formação e atuação do pedagogo em variados espaços; d) políticas educacionais; e) educação de jovens e adultos; f) as instituições escolares de formação, sua história e seus sujeitos. Diversas pesquisas e trabalhos desenvolvidos pelo grupo permeiam essas temáticas de forma interdisciplinar. A seguir serão detalhadas algumas destas atividades.

A formação continuada de professores da Educação de Jovens e Adultos - EJA é tema da pesquisa denominada "Educação de Jovens e Adultos: uma análise do impacto do programa de formação 'UFOP com a Escola' no trabalho docente de professores da Região dos Inconfidentes", que teve entre os objetivos verificar o impacto da formação oferecida pelo programa aos professores integrantes e se estas ações contribuíram para a mudança da prática dos docentes da EJA nos municípios da Região dos Inconfidentes (Mariana, Ouro Preto, Acaiaca Itabirito e Diogo de Vasconcelos). Ela foi desenvolvida em parceria com o Núcleo de Pesquisa sobre as Licenciaturas e a Formação de Professores (NEPEL-UFOP), no período de 2012 a 2014.

Dentre os trabalhos desenvolvidos, podemos citar Araújo, Freitas, Martins e Wiltemburg (2013) que discutem aspectos dessa formação na vida profissional dos professores da EJA e alguns dados sobre o perfil dos profissionais participantes dessa pesquisa. Grande parte dos entrevistados atua no ensino médio, seguindo pelo ensino fundamental II, o fundamental I e outros níveis e modalidade de ensino. Eles são iniciantes na modalidade EJA, mas nem todos são iniciantes na carreira docente. A partir deste estudo foi possível criar um banco de dados para auxiliar em pesquisas futuras sobre a formação inicial e continuada destes profissionais, de modo a conhecer a realidade destes.

Em outro artigo sobre o impacto do programa UFOP com a Escola, Araújo, Martins e Oliveira (2013) apontam que este não conseguiu 
chegar ao seu público-alvo, pois uma pequena parte dos entrevistados confirmaram ter participado de alguma das ações do programa. $\mathrm{E}$ entre os cursos oferecidos pelo UFOP com a Escola, apenas um deles era dirigido especificamente aos professores da EJA. E voltava-se para solidificação das ações na formação de professores nesta modalidade e fortalecimento da formação continuada. Essa pesquisa possibilitou discutir os "possíveis caminhos para se (re) pensar políticas e ações de formação inicial e continuada que atendam às necessidades destes sujeitos que atuam como educadores da EJA" (ARAÚJO; MARTINS; OLIVEIRA, 2013, p. 13149). Além de ser essencial o diálogo constante entre os parceiros do programa e o compromisso de trabalho em conjunto de ambas as partes.

Compreendemos que estes trabalhos discutem temáticas importantes sobre a EJA, as quais concorrem para a proposição de ações que visem a formação de acordo com as demandas específicas dos professores da região.

O Observatório Educacional da Região dos Inconfidentes (OBERI), iniciado em 2014, auxilia na promoção de pesquisas ligadas aos temas da política educacional, formação, condição e profissionalização de professores e história da educação. Ele reuniu, organizou e analisou dados e informações sobre a educação básica na região, como forma de conhecer o campo de pesquisa. Foi desenvolvido em parceria como os Programas de Pós-graduação em Educação, Letras e História, do Instituto de Ciências Humanas e Sociais da UFOP. Além de ser visto como um espaço de conexão entre as redes de investigação latina e ibero-americana para o estabelecimento de parcerias e aprofundamento das relações acadêmicas.

O OBERI acolheu seis subprojetos associados que contemplavam as seguintes temáticas ${ }^{2}$ : o perfil dos professores da educação básica; os pedagogos e os desafios da prática escolar; os professores iniciantes da educação de jovens e adultos; o início da docência na educação infantil; a juvenilidade da educação de jovens e adultos; o mal estar docente; a avaliação do sistema educacional.

\footnotetext{
${ }^{2} \mathrm{~A}$ produção do grupo foi recentemente publicada em um livro organizado pelos coordenadores do OBERI, J.R.L Jardilino e Margareth Diniz (org). Universidade e a Escola Pública: Experiências de pesquisas colaborativas na formação de professores(as). Curitiba: Editora Appris, 2020.
}

Araújo e Nunes (2014, p. 3641) descrevem os objetivos do OBERI:

[...] buscar e sistematizar informações junto aos atores educacionais da Região dos Inconfidentes, de modo a fornecer subsídios ao debate e a capacidade de intervenção destes atores na discussão e implantação de políticas públicas educacionais nos municípios e distritos da região; coletar informações e disseminar os resultados das pesquisas realizadas nos eixos do Observatório com base na relação cooperativa dos programas parceiros (Rede de Investigadores do ICHS) e, de outro, pesquisadores/as do campo que detêm ou podem produzir informações estratégicas para a referida região; organizar a base de dados comuns para a promoção de debate e pesquisas sobre temáticas emergentes relativas à educação nos municípios da Região dos Inconfidentes.

O OBERI visa o trabalho conjunto de investigadores com o propósito de produzir informações sobre os profissionais e escolas da região para que se possa discutir políticas públicas educacionais, trocar conhecimentos e resultados de pesquisa para a compreensão do processo educacional e a formação docente.

De acordo com as pesquisadoras, os trabalhos que são vinculados ao observatório tentam responder as seguintes indagações: "Quais os principais problemas que atingem a Educação na Região dos Inconfidentes? Quais práticas docentes são desenvolvidas para atingir tais problemas? Quem são os sujeitos a que se destinam estas práticas? Como são avaliados docentes e discentes?" (ARAÚJO; NUNES, 2014, p. 3642).

O trabalho de Jardilino e Diniz (2019) discute os resultados de um dos subprojetos denominado "Perfil dos(as) professores(as) da 
Região dos Inconfidentes, realizado com os professores da educação básica. Os dados foram organizados em três eixos: trajetória na formação, trajetória na carreira e mal-estar docente. Dentre os resultados, destacamos que grande parte da formação continuada para os professores era ofertada pelas Secretarias Municipais de Educação e que o número de participantes das ações de formação organizadas pela universidade era bem pequeno, fato que confirma "certo distanciamento entre a formação inicial e continuada, por conseguinte, entre a universidade e escola" (JARDILINO; DINIZ, 2019, p. 6). Já com relação ao mal-estar docente, a maioria das professoras relataram dificuldades em "lidar com o/a aluno/a, com as situações que não são recorrentes, que são 'anormais' dentro da lógica sociocultural pré-estabelecida pela escola" (JARDILINO; DINIZ, 2019, p. 6). Os pesquisadores apontam para a necessidade de olhar para os discursos como meio de reinvenção e construção de mecanismos que permitam que as professoras tenham a oportunidade de se recolocarem diante da sua prática, da sua subjetividade e das diferenças entre os alunos.

Já no trabalho "Formação de mulheres professoras afrodescendentes: condição e profissão docente na Região dos Inconfidentes", Jardilino e Diniz (2016) discutem os dados da pesquisa sobre o perfil dos professores da referida região sob 0 viés das mulheres professoras afrodescendentes, retratando sua subjetividade, identidade, atuação profissional e condição docente. Eles destacam aspectos da categoria sexo/gênero referentes ao reconhecimento dos próprios sujeitos sobre essa categoria, a pertença étnico-racial por meio da autodeclaração e o reflexo disso na identidade docente. Os pesquisadores afirmam que há a necessidade de "possíveis discussões junto aos gestores municipais para implementação de políticas públicas visando à melhoria da educação básica na Região dos Inconfidentes" (JARDILINO; DINIZ, 2016, p. 98).

O OBERI também abriga o Programa Caleidoscópio de pesquisa e extensão que tem como proposta de trabalho "uma ação multidisciplinar e interinstitucional de saberes e práticas que buscam analisar e intervir em realidades do ensino superior, do ensino fundamental, médio e da comunidade em geral, articulando a pesquisa, o ensino e a extensão(...)" (ARAÚJO; NUNES, 2014, p. 3643).
O OBERI tem como eixo de trabalho e formação o ensino, pesquisa e extensão interligando várias ações interdisciplinares e multidisciplinares que contemplam aspectos da formação, profissão docente, condição e carreira, mulheres professoras, afrodescendentes no que refere aos sentidos da experiência do sujeito professor, suas vivências pessoal e profissional e outras necessidades ligadas à sua sobrevivência e da comunidade em que estão inseridas.

A pesquisa ligada ao programa Observatório da Educação (OBEDUC), edital CAPES n. 049/2012,2013 - 2017, "Desenvolvimento Profissional docente e Inovação Pedagógica: estudo exploratório sobre contribuições do PIBID", teve como tema o desenvolvimento profissional e inovação pedagógica dos docentes da educação básica que atuaram no Programa Institucional de Bolsa de Iniciação à Docência (PIBID) como professores supervisores em algumas cidades dos estados do Ceará, Minas Gerais e São Paulo. Dos vários objetivos desta pesquisa, destacamos:

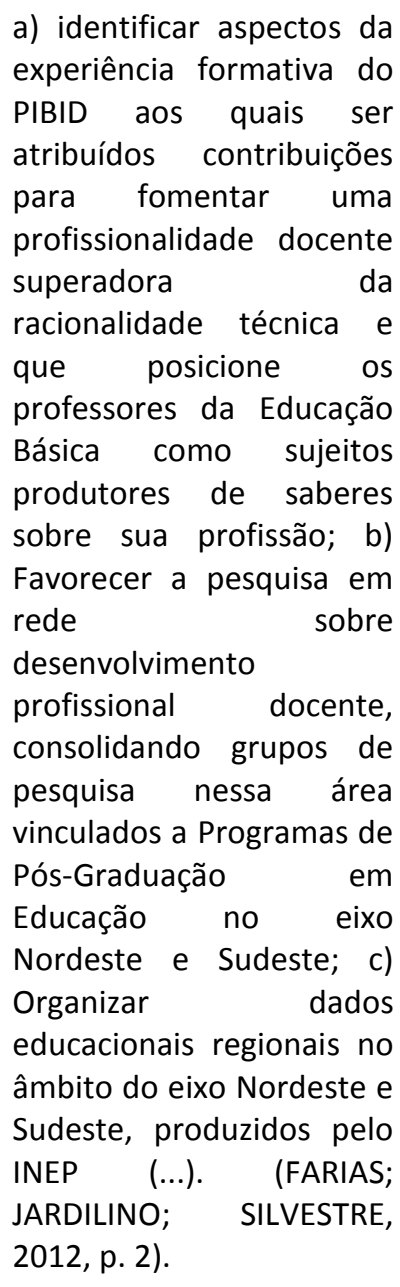

Ela tratou da formação continuada e o desenvolvimento profissional docente (DPD), 
como também da formação pela pesquisa. Além de ser um espaço de formação de pesquisadores da educação básica e da universidade por meio da pesquisa em rede. Há a construção do processo formativo de docentes em diferentes frentes que articula a troca de experiências e conhecimentos entre pesquisadores experientes, pesquisadores em formação e as instituições de ensino da universidade e das escolas participantes. O tema da formação continuada também foi tratado por Jardilino e Oliveri (2013) em outro trabalho.

Esta pesquisa contribuiu para fomentar a pesquisa em rede no Grupo, com a participação de três IES: Universidade Estadual do Ceará (UECE), Universidade Federal de São Paulo (UNIFESP) e Universidade Federal de Ouro Preto (UFOP) $)^{3}$. Favoreceu a consolidação dos grupos de pesquisa das respectivas instituições, a partir da formação de pesquisadores na graduação, pósgraduação e na educação básica. O livro organizado por Farias, Jardilino e Silvestre (2015) aborda alguns trabalhos produzidos no âmbito dos três núcleos de pesquisa. Alguns estudantes que participaram deste projeto prosseguiram na jornada de formação acadêmica, enveredando para o mestrado e doutorado, atuam como docentes ou gestores nas escolas públicas de educação básica, outros integram os conselhos municipais de educação da Região dos Inconfidentes.

As etapas de pesquisa, desde o levantamento de fontes bibliográficas, seu estudo, a investigação das escolas participantes e dos docentes que atuaram no programa, o levantamento dos indicadores sociais dos municípios, a coleta, a organização de dados, sua análise e discussão dos resultados foram desenvolvidas por todos os participantes nos três núcleos de pesquisa. Para análise dos dados foram criadas duas categorias centrais: desenvolvimento profissional docente e inovação pedagógica, as quais divididas em subcategorias e descritores para auxiliar em sua análise e compreensão, conforme discutido por Jardilino e Araújo (2019).

\footnotetext{
${ }^{3}$ Os resultados desta pesquisa do Núcleo Ouro Preto (UFOP) estão registrados no livro publicado pelos coordenadores da pesquisa na região, os professores J.R.L. Jardilino e Regina M.B de Araújo. In. Desenvolvimento profissional docente e inovação pedagógica: Formação de professores na região dos inconfidentes - OBEDUC e PIBID. Curitiba, CRV, 2019.
}

Foram produzidos vários trabalhos ${ }^{4}$ que contemplaram os aspectos do campo da formação continuada de professores, do desenvolvimento profissional, da inovação pedagógica e das políticas de formação nas cidades de Ouro Preto e Mariana, as quais têm projetos do PIBID em algumas escolas.

O trabalho de Araújo, Batista e Maia (2017, p. 150) trata dos aspectos relativos à subcategoria "Sujeitos da profissão" que, conforme as pesquisadoras tinham o interesse em saber "como o docente define a sua identidade profissional e a relação do trabalho com a sua pessoalidade". Com relação aos desafios da carreira, Araújo, Batista e Maia (2017) relatam que a desvalorização profissional é o maior desafio apontado pelos entrevistados. A inserção no PIBID, para os entrevistados, trouxe a oportunidade de refletir sobre 0 fazer pedagógico, a própria carreira e para a constituição da identidade profissional a partir de uma postura crítica e consciente. Além de o programa se revelar como uma oportunidade diferenciada de formação continuada, troca de experiências e conhecimentos com os licenciandos e com a universidade.

Os professores entrevistados reconhecem e são conscientes da importância do seu papel de coformador no processo formativo dos futuros professores. E por fim, Araújo, Batista e Maia (2017, p. 160) apontam que os "docentes disseram que o PIBID vem auxiliando a escola a superar práticas isoladas rumo a uma práxis cooperativa". E que o programa "agrega valores e experiências para todos os envolvidos, além de levar melhorias para a instituição na forma de recursos materiais e novas metodologias".

Jardilino, Oliveri e Silva (2017) discutem no texto "Desenvolvimento profissional e inovação pedagógica: a experiência de formação dos professores supervisores do PIBID na Região dos Inconfidentes - MG" algumas questões concernentes a experiência de formação dos professores supervisores com relação ao desenvolvimento profissional e a inovação pedagógica. Eles afirmam que o PIBID também contribuiu para a "ressignificação das práticas pedagógicas e para desenvolvimento profissional" (JARDILINO; OLIVERI; SILVA, 2017, p. 80). O processo de ressignificação das práticas concorreu para a melhoria da relação professor-

\footnotetext{
${ }^{4}$ Alguns trabalhos produzidos pelos núcleos de pesquisa UECE, UFOP e UNIFESP estão disponíveis no site https://obeducuece.wixsite.com/pesquisa.
} 
aluno, despertando o interesse e a adesão dos educandos no processo de ensino e aprendizagem.

As atividades teóricas e práticas desenvolvidas pelo programa foram integradas gradualmente ao trabalho pedagógico desenvolvido na sala de aula. Este processo de integração colaborou para a reflexão coletiva sobre a prática, dando a ela variados significados. A relação dos professores com o conhecimento também foi ampliada por meio da participação em novas experiências de formação, "proporcionando-lhes um novo olhar diante dos conhecimentos já adquiridos, como também para com os novos saberes, dando novos contornos à sua formação pessoal e profissional" (JARDILINO; OLIVERI; SILVA, 2017, p. 87).

Farias, Jardilino e Silvestre (2017, p. 120) afirmam que esta pesquisa sobre o DPD dos professores supervisores do PIBID:

constitui-se como uma Rede de Formação que extrapolou o objetivo primeiro de ser uma pesquisa realizada em âmbito nacional, na busca de identificar aspectos da experiência formativa no programa governamental de incentivo a formação do futuro professor, ao qual possa ser atribuídas contribuições para fomentar uma profissionalidade docente que supere a racionalidade técnica.

Desta forma, ao congregar docentes da educação básica e da universidade, alunos da graduação e pós-graduação de regiões diferentes, este projeto promoveu a formação pela pesquisa destes sujeitos a partir do diálogo e reflexão, tendo-os como agentes ativos de seus processos de formação e desenvolvimento.

Com relação ao tema das políticas de formação, o trabalho de Jardilino, Farias e Oliveri (2016), traz uma discussão sobre os Planos Municipais de Educação (PME) de um dos municípios da Região dos Inconfidentes, sob a perspectiva do desenvolvimento profissional docente e da formação continuada. Os documentos analisados são dos períodos de 2006 - 2014 e 2015 - 2024. A partir da comparação entre eles, os pesquisadores procuraram compreender como estas temáticas são abordadas. Eles afirmaram que os dois documentos seguem as orientações dos Planos Nacionais de Educação (PNE's) ao contemplar aspectos relativos ao DPD, a formação continuada e a valorização da profissão. No entanto, algumas metas que constam no PNE (2006 -2014) não foram referidas no segundo PNE (2015 -2024). Fato que corrobora o diagnóstico impreciso sobre as condições dessa temática no município, levando a concluir que esses documentos são organizados por uma administração e não levados adiante pela nova administração no mandato seguinte.

Já o tema das instituições escolares e formação de professores é retratado na dissertação de mestrado de Pedruzzi (2016), que teve como objeto de pesquisa a Escola Normal de Ouro Preto 1835 - 1889, discutindo o seu processo de implantação e funcionamento como instituição formadora no contexto imperial. Ela foi a primeira instituição mineira que tentou proporcionar uma formação específica para docentes no magistério público mineiro. A pesquisadora destaca que esta instituição passou por várias dificuldades e períodos de instabilidade, ao tentar cumprir seu objetivo de formação. A Escola Normal de Ouro Preto ocupou um papel relevante e central na formação dos professores mineiros no século XIX, em uma época em que ainda era pouco percebida a necessidade da formação e profissionalização dos docentes em Minas Gerais e no Brasil (PEDRUZZI, 2016).

E para compor o quadro das pesquisas desenvolvidas no âmbito do grupo, selecionamos trabalhos que discutem a produção científica sobre algumas temáticas do campo da formação e profissão docente. Estes trabalhos tipo "estado da arte" e "estado do conhecimento" auxiliam no entendimento do movimento do campo e na compreensão processo educacional no Brasil e no exterior.

O campo de pesquisa sobre formação de professores é tratado por Jardilino et al. (2011) sob a perspectiva das pesquisas apresentadas nos Grupos de Trabalhos (GTs) de Formação de professores, Didática, Currículo, Arte e Educação, Educação Matemática e Educação e Comunicação, da Associação Nacional de Pós-Graduação e Pesquisa em Educação (Anped). Seu objetivo é compreender o modo como se estrutura o campo de pesquisa da área da educação ao longo da década de 2000-2010. 
A Educação de Jovens e Adultos no Brasil foi tema de discussão no trabalho produzido por Araújo et al. (2013). Neste trabalho os autores fazem um levantamento da produção científica sobre as políticas públicas para a Educação de Jovens e Adultos (EJA), apresentada no Grupo de Trabalho Educação de Pessoas Jovens e Adultos (GT 18) da Anped, nos anos de 2011 e 2012. Os autores apontaram o número reduzido de pesquisas apresentadas na Anped, GT 18, que discutem o financiamento da educação de jovens e adultos. Houve continuidade com relação ao aumento do número de trabalhos publicados sobre os programas federais para a EJA. Além disso, eles notaram o interesse da academia em compreender, analisar e contribuir para o aprimoramento e promoção de políticas para esta área.

No trabalho "Uma análise da produção sobre o PIBID (2008-2013): o que dizem as dissertações da região Sudeste", Cruz, Pedruzzi e Silva (2015) fazem uma análise das teses e dissertações sobre o PIBID produzidas na região Sudeste no período compreendido entre 2008 a 2013. Eles obtiveram apenas 5 dissertações que tratavam do tema. A abordagem qualitativa esteve presente nos trabalhos encontrados e os instrumentos mais utilizados foram a observação etnográfica, o estudo de caso, entrevistas semiestruturadas e acompanhamento de grupos. Já entre os aspectos discutidos nestes trabalhos temos a convivência e interação entre os sujeitos participantes dos projetos do programa, o desenvolvimento profissional docente e a visão da escola como um espaço de aprendizagem e formação por meio do trabalho colaborativo.

\section{A PRODUÇÃO ACADÊMICA AO LONGO DA CONSOLIDAÇÃO DO FOPROFI: REFLEXOS NO ANO DE 2019}

O Grupo de Pesquisa Formação e Profissão Docente tem consolidado suas linhas de pesquisa e cumprindo um papel importante sobre a formação de docentes para atuação nos espaços da universidade e da educação básica em nível regional e nacional.

A partir do levantamento e discussão de alguns trabalhos produzidos, percebemos que várias temáticas no campo da formação, da profissão e instituições formadoras de professores foram incorporadas às discussões. Isto reflete não apenas nas pesquisas, mas também na inserção social do FOPROFI ao contribuir para a discussão de questões relativas às demandas dos profissionais da educação da região, por meio de uma relação recíproca em que universidade e escola são parceiras neste processo de reflexão, colaborando mutuamente para a formação de seus profissionais.

Ao final do seu primeiro ano de funcionamento, foram produzidos pelo grupo seis artigos, cinco capítulos de livros e 18 apresentações de trabalho. Já no levantamento do ano de 2019 foram identificados 77 trabalhos, distribuídos conforme o gráfico3;

Gráfico 3. Produção acadêmica FOPROFI/UFOP- 2019

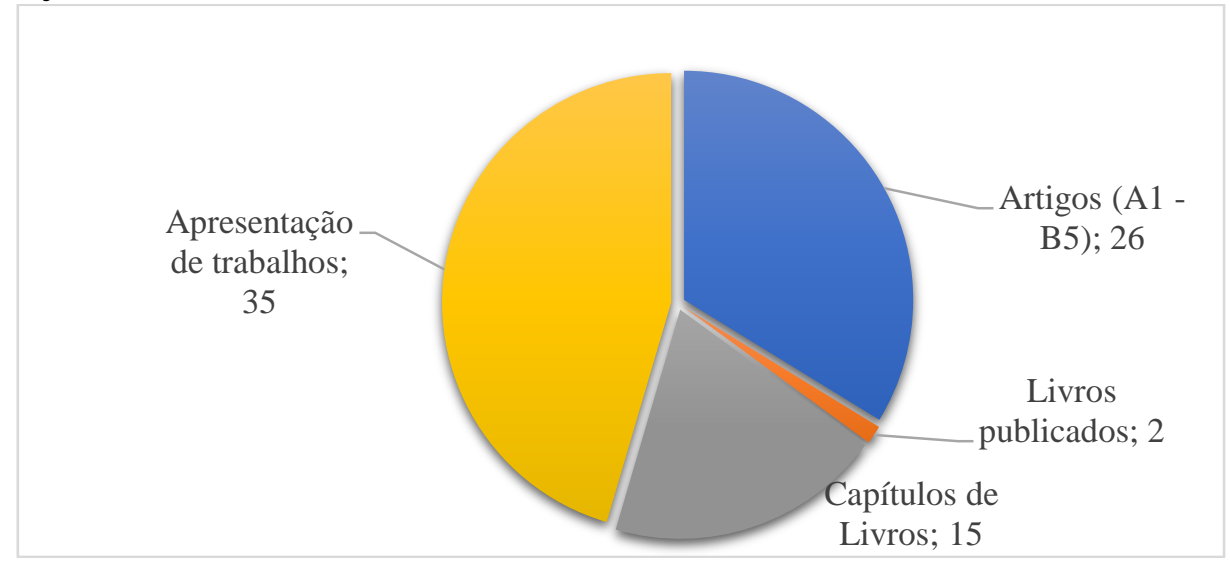

Fonte: Os autores

Nota: Organizado a partir do levantamento da produção do FOPROFI.

Podemos observar um aumento com relação à publicação de livros, de capítulos de livros, com destaque para a produção de artigos no período relativo ao ano de 2019 . Os dados 
demonstram a consolidação do grupo e o importante papel desenvolvido no processo educativo de formação dos sujeitos. A partir do levantamento e discussão de alguns dos trabalhos produzidos, percebemos que várias temáticas no campo da formação, da profissão docente e instituições formadoras de professores vem ganhando novos contornos, por meio da parceria entre universidade e escola, e aprofundando cada vez mais nos mais diferentes aspectos, constituindo-se em eixos estruturantes.

Os eixos estruturantes têm se tornado fios condutores que se unem na construção de novos temas e projetos, conforme nos apresenta o quadro 1 , contribuindo para o crescimento e aprendizagem de todo o grupo, atentando-se para as dimensões da pessoa e do sujeito professor e pesquisador.

Quadro 1. Eixos e Temas das pesquisas - 2019

Eixos

\begin{tabular}{cl}
\hline & Pesquisa colaborativa na formação continuada \\
& Formação continuada na educação básica e o papel do coordenador \\
& pedagógico \\
& Docência em escola prisional, ensino superior e educação básica \\
Formação e Docência & Formação do educador de jovens e adultos, pedagogos e licenciados \\
& em Matemática \\
& Ciclo profissional e docência universitária \\
\hline & Desenvolvimento profissional, política pública de formação, inovação \\
& pedagógica e colonialidade e Pedagogias do Sul \\
Carreira; Profissão & Dendições de trabalho, precarização, carreira e valorização docente \\
e DPD & básica \\
& $\begin{array}{l}\text { Programas de DPD nos Institutos Federais } \\
\text { Escolha profissional de egressos da pedagogia }\end{array}$ \\
\hline Políticas de Formação & Política educacional no ensino superior e educação básica \\
& Relação família - escola, valorização da docência e políticas públicas \\
& Políticas de formação dos pedagogos e perfil desses profissionais \\
& Políticas de inclusão e diversidade na Formação de Professores \\
\hline História da formação de professores nas Escolas Normais \\
Educação rural latino-americana \\
PIBID-EJA e formação inicial dos pedagogos \\
Sujeitos, narrativas e saberes docentes \\
Classes multisseriadas e educação de jovens e adultos \\
Instituições \\
Pesquisa cooperativa e construção de saberes na educação de jovense \\
adultos \\
Pesquisa qualitativa na educação e grupo focal \\
Educação em espaços não formais \\
Educação econômica e o papel da escola
\end{tabular}

Fonte: Os autores

Nota: Organizado a partir do levantamento da produção do FOPROFI.

Os trabalhos desenvolvidos tratam sobre variadas questões, o que contribui para a compreensão das temáticas de formação de professores, política educacional e instituição escolar, além de favorecerem a discussão dos espaços de formação e metodologias de pesquisa.

Dentre os vários objetos de estudo e metodologias de pesquisa, apontamos alguns trabalhos como a investigação realizada por Nunes et al. (2019) sobre os programas de 
desenvolvimento profissional docente da Educação Profissional Técnica e Tecnológica, a partir de uma pesquisa bibliográfica e documental. Os resultados apontaram a existência de poucos estudos com os docentes da educação técnica e tecnológica e a inexistência de programas de desenvolvimento profissional nos Institutos Federais de Minas Gerais.

Araújo, Nunes e Lucindo (2019) discutem as Diretrizes Curriculares de 2006 e seus efeitos na formação do pedagogo. E tratam aspectos relativos à atuação do pedagogo na sociedade e na educação, a partir da perspectiva dos egressos do curso de Pedagogia de duas instituições de ensino, uma privada e outra pública. Os resultados apontam para a importância desse profissional para a educação e, ao mesmo tempo, revelam a sua desvalorização social.

O desenvolvimento profissional docente é discutido por Jardilino e Sampaio (2019) no Plano Nacional de Educação (2014-2024). Os autores examinam o DPD utilizando os conceitos construídos por pesquisadores nacionais e internacionais. Eles destacam que há falta de articulação entre os entes federados na implementação do plano, fato que colabora para que não ocorra o cumprimento das metas. $\mathrm{E}$ observam que é preciso mais estudos no aprofundamento das questões que envolvem o DPD. O tema do DPD tem ganhando destaque nas pesquisas do grupo como se pode ver na produção de membros da equipe (JARDILINO; SAMPAIO, 2018, 2018a, 2020 - prelo).

O trabalho de Araújo, Silva e Silva (2019) aborda o tema da formação continuada dos professores na Região dos Inconfidentes, discutindo as implicações que esta pode trazer para a prática profissional dos docentes da rede pública de educação básica. De acordo com os pesquisadores, os resultados revelam que existe uma concepção frágil sobre o tema por parte dos participantes da pesquisa, ausência com relação as ações institucionais que promovam o trabalho crítico e coletivo de formação, sendo necessário o aprofundamento das políticas educacionais para que se tenha uma educação emancipadora e transformadora da escola.

Em uma perspectiva de ampliação da concepção de formação, Silva, Oliveira e Carvalho (2019) tratam de aspectos relativos à formação do professor de Matemática no que diz respeito às escolhas, vivências e circunstâncias na constituição do ser professor, por meio do memorial formativo, analisando as convergências e singularidades dos processos de formação. No texto, elas apontam que a família e os professores exercem um papel importante na escolha da profissão. A formação do professor de Matemática ocorre pela influência dos professores, afinidade pela área e vivências na própria profissão e outras experiências como a referência de si mesmo como bom aluno.

As condições de trabalho e valorização docente são temas do trabalho produzido por Gomes, Nunes e Pádua (2019). Entre os fatores relativos às condições de trabalho e a complexidade das atividades no exercício da profissão, o trabalho destaca a remuneração, o plano de carreira, a avaliação de desempenho e a infraestrutura física e material das escolas, os quais interferem no modo de ser e estar na profissão. A condição de trabalho desfavorável é um fator que coopera para o adoecimento dos professores e pela busca por outras profissões que não seja à docência. Desta forma, compreendem a importância de se ter políticas promovam a melhoria das condições de trabalho e da saúde dos docentes.

E por fim, Mathias e Jardilino (2019) ampliam o lócus da formação para uma experiência docente pouco veiculada no nosso campo, que se trata da formação do professor de Música, ou de Artes, na compreensão mais ampliada dessa formação para atuação na educação básica. Para isso, discutem a Lei no $11.769 / 2008$ que institui a música como conteúdo da educação básica, utilizando a teoria dos ciclos de políticas para a análise documental. Para esses autores, é preciso que outras políticas sejam aprovadas para que a música se torne uma disciplina na escola de forma permanente. Apenas a aprovação da lei não garante a formação de professores e a adequação das instituições de ensino para que se tenha a estrutura necessária ao desenvolvimento da educação musical.

Os projetos do OBEDUC e OBERI, já concluídos, impulsionaram outras pesquisas de mestrado e doutorado em andamento com temáticas ligadas às políticas educacionais e a formação de professores; ao desenvolvimento profissional docente e a avaliação; à atuação dos pedagogos nos espaços de educação não formais; à docência universitária e as políticas de educação superior; à história das instituições de formação; políticas e formação para atuação na educação de jovens e adultos; entre outras temáticas. 
Assim, há o entrelaçamento das pesquisas macro e pesquisas micro e continuidade de um processo de entendimento do campo da formação de professores, das instituições e seus sujeitos e da política educacional.

\section{CONSIDERAÇÕES FINAIS SOBRE A FORMAÇÃO DE PROFESSORES NO FOPROFI}

A educação no Brasil tem percorrido um longo caminho na busca pela efetivação do acesso, permanência e qualidade do ensino para toda a população, em todos os níveis de ensino. No que tange ao ensino superior, temos visto a tentativa de desmantelamento da universidade pública em seus pilares, ou seja, o ensino, a pesquisa e a extensão, ao passo que a educação básica também tem sofrido consequências por conta da redução dos investimentos e falta de políticas públicas específicas. Estas ações impactam na profissão e formação docente, a qual está alicerçada em cursos e outras atividades que, muitas vezes, não levam em conta as necessidades e especificidades das diversas áreas de formação, atuação, perfil, vivências dos professores e o contexto educacional em que desenvolve suas atividades.

A literatura da área de formação de professores tem discutido a formação em um processo contínuo em que o docente é o condutor do seu próprio percurso formativo e de desenvolvimento profissional, de acordo com Zeichner (1995), Nóvoa (1995), García (1999). Há a valorização da pessoa e do profissional neste conceito, pelo fato de o docente ser considerado como produtor de conhecimentos, capaz de refletir e interligar os saberes adquiridos ao longo da sua vida profissional e na vida em sociedade.

Já Lüdke (2004) e Demo (2006) tratam da formação para a pesquisa a partir do tipo de pesquisa que é realizada na educação básica e a preparação do professor para desenvolver este trabalho na sala de aula e na escola. E reconhecem a importância desta para a sua própria formação e para o ensino e aprendizagem dos alunos. Mizukami (2004) discute a formação continuada por meio da parceria universidade e escola, a qual colabora para o desenvolvimento profissional por meio da reflexão sobre a aprendizagem da docência e reflexão sobre os seus processos de aprendizagem. E Reali (2004) concebe o trabalho colaborativo e a parceria entre universidade - escola como caminhos para a análise das práticas e construção de novos conhecimentos.

Inserido neste contexto como um grupo de estudos e formação de professores e pesquisadores, o FOPROFI/UFOP tem como premissa a interseção das diversas áreas do campo da formação docente. Desta forma, promove o contato entre estudantes de graduação, docentes da educação básica e ensino superior e destes com outras áreas e temas que vão além do seu objeto de pesquisa ou trabalho, pois estabelece relações com as escolas, as instâncias de gestão e a sociedade.

O trabalho com projetos de pesquisa desenvolvidos com a participação de toda a equipe propicia novos horizontes de pesquisa e de formação, pelo fato de que há a discussão de novas temáticas, de novas metodologias e teorias que auxiliam na compreensão da realidade educacional brasileira e na formação de sujeitos críticos e atentos a realidade que os cerca, mas que nem sempre estão acessíveis a todos os envolvidos diretamente ou indiretamente com a educação.

Por isso, entendemos ser extremante importante a promoção da formação por meio das redes de pesquisa, sejam elas articuladas com outras instituições de ensino ou dentro do próprio grupo de pesquisa. A organização de grandes pesquisas que se subdividem em projetos menores ou entrecruzam vários campos de conhecimento, possibilita a troca de conhecimentos, experiências. $\mathrm{E}$ abre várias possibilidades para se pensar o campo da formação, profissão docente e das instituições de formação sob diferentes aspectos.

A expansão do grupo de pesquisa para fora dos muros da universidade promove a integração entre universidade e as demais instituições que a cerca. Em contexto regional, esta expansão é um fator de impacto social da universidade ao colocar em discussão os desafios educacionais nos diferentes níveis e modalidades de ensino e de busca de alternativas em conjunto entre universidades, escolas e secretarias de educação para a melhoria da educação na Região dos Inconfidentes. O FOPROFI vai além do nível regional de troca de experiências e conhecimentos ao estabelecer também relações outras instituições de ensino superior nacionais e internacionais que por meio de suas pesquisas e conhecimentos compartilhados auxiliam na compreensão da realidade educacional da região e do país. 
E, por fim, no atual cenário de discussão sobre as mudanças no contexto educacional com a necessidade de se discutir a educação a distância e o ensino remoto, os quais repercutem na formação e nas condições da profissão docente, nas formas de ensinar e aprender. Além de outras questões de ordem social e econômica que foram agravadas com o atual cenário de emergência em saúde pública mundial, é imprescindível que as universidades, as escolas de educação básica, os sindicatos e outras instâncias da sociedade discutam as possibilidades de mudança, suas necessidades e os impactos dessa realidade na formação de professores, na escola, famílias e na comunidade.

\section{AGRADECIMENTOS}

Agradecemos as agências nacionais e estadual de fomento à pesquisa pelo apoio ao grupo - Conselho Nacional de Desenvolvimento Científico e Tecnológico (CNPq), à Coordenação de Aperfeiçoamento de Pessoal de Nível Superior (CAPES) à Fundação de Amparo à Pesquisa do Estado de Minas Gerais (FAPEMIG) pela concessão das bolsas de produtividade, de mestrado, de doutorado e de Iniciação Científica que o grupo vem recebendo durante estes anos de atividades. De igual modo agradecemos o apoio à pesquisa institucionalizada da Universidade Federal de Ouro Preto por meio dos editais específicos nos quais o grupo tem sido beneficiado com a concessão de apoio financeiro. Por fim, desejamos agradecer a todos os parceiros destas pesquisas, mas em especial aos colegas parceiros e professores-pesquisadores da Educação Pública das redes de ensino Municipais e Estadual de Minas Gerais localizados na Região dos Inconfidentes ${ }^{5}$, que compõem a delimitação espacial de atuação do grupo.

Os autores declaram não haver qualquer potencial conflito de interesse que possa interferir na imparcialidade deste trabalho científico.

\section{REFERÊNCIAS}

ANDRÉ, M. Formação de professores: a constituição de um campo de estudos. In: Educação, Porto Alegre, v. 33, n. 3, p. 174-181, set./dez. 2010.

ARAÚJO, R. M. B. et al. Políticas para educação de jovens e adultos no Brasil: a produção da área

\footnotetext{
${ }^{5}$ Confira os apontamentos na nota 1 deste artigo.
}

nos anos de 2011 e 2012 veiculadas na ANPED. Ecos Revista Científica, São Paulo, n. 32, p. 67-84, set./dez. 2013. Disponível em: https://periodicos.uninove.br/eccos/article.

Acesso em: 23 jul. 2020. DOl: $\underline{10.5585 / \text { eccos.n32.4624 }}$

ARAÚJO, R. M. B. et al. A Educação de Jovens e Adultos na Região dos Inconfidentes: considerações sobre o perfil dos professores. In: CONGRESSO NACIONAL DE EDUCAÇÃO EDUCERE, 11., Curitiba, 2013. Anais... Curitiba: EDUCERE, 2013, p. $7682-7694$.

ARAÚJO, R. M. B.; MARTINS, J. C. C.; OLIVEIRA, R. K. A Universidade e a formação continuada de professores da EJA: ações extensionistas e o trabalho docente na Região dos Inconfidentes. In: CONGRESSO NACIONAL DE EDUCAÇÃO EDUCERE, 11., Curitiba, 2013. Anais... Curitiba: EDUCERE, 2013, p. 13142-13150.

ARAÚJO, R. M. B.; NUNES, C. M. F. Formação docente e desenvolvimento profissional: novos dispositivos formativos e sua relação com o ensinar e o aprender. In: ENCONTRO NACIONAL DE PRÁTICA DE PESQUISA - Endipe, 17., Fortaleza, 2014. Anais... Fortaleza: Endipe, 2014, p. $3638-3647$.

ARAÚJO, R. M. B. de.; BATISTA, V. A.; MAIA, V. M. $R$. Contribuições do programa institucional de bolsas de iniciação à docência - PIBID na carreira de professores experientes. Formação Docente Revista Brasileira de Pesquisa sobre Formação dos Professores. Belo Horizonte, v.09, n. 16, p. 143-162, jan./jun. 2017. Disponível em: https://revformacaodocente.com.br/index.php/r $\mathrm{bpfp/article/view/167.} \mathrm{Acesso} \mathrm{em:} 23$ jul. 2020. DOI: $10.31639 /$ rbpfp.v9i16.167

ARAÚJO, R. M. B.; NUNES, C. M. F. LUCINDO, N. I. As vozes dos egressos de Pedagogia de uma IES pública federal: entre as políticas e a formação de pedagogos. Colloquium Humanarum, v. 16, p. 418, 2019. Disponível em: http://journal.unoeste.br/index.php/ch/article/vi ew/2494/2689. Acesso em: 23 jul. 2020 DOl: 10.5747/ch.2019.v16.n1.h399

ARAÚJO, R. M. B.; SILVA, M. D.; SILVA, M. C. A formação continuada de professores da educação básica: concepções e desafios na perspectiva dos docentes. Revista @mbienteeducação. São 
Paulo: Universidade Cidade de São Paulo, v. 12, n. 3, p. 17-38 set/dez 2019. Disponível em: http://publicacoes.unicid.edu.br/index.php/ambi enteeducacao/article/view/758. Acesso em: 19 jul. 2020.

DOI:

10.26843/ae19828632v12n32019p17a38

CUNHA, M. I. O tema da formação de professores: trajetórias e tendências do campo na pesquisa e na ação. In: Educação e Pesquisa., São Paulo, v. 39, n. 3, p. 609-626, set. $2013 . \quad$ Disponível em: https://www.scielo.br/scielo.php?script=sci artte xt\&pid=S1517-

$97022013000300004 \& \operatorname{lng}=p t \&$ tlng=pt. Acesso em: 20 jul. 2020 DOI: 10.1590/S151797022013005000014

CRUZ, D. R. N.; PEDRUZZI, J. S.; SILVA, A. R. Uma análise sobre o PIBID (2008-2013): O que dizem as dissertações da Região Sudeste? In: PEDAGOGÍA 2015: ENCUENTRO INTERNACIONAL POR LAUNIDAD DE LOS EDUCADORES, 2015, Havana. Anais do Encuentro Internacional por la Unidad de los Educacores, Havana, 2015. p. 1-14.

DEMO, Pedro. Pesquisa: princípio científico e educativo. 12.ed. São Paulo: Cortez, 2006.

FARIAS, I. M. S.; JARDILINO, J. R. L.; SILVESTRE, M. A. Desenvolvimento Profissional Docente e Inovação Pedagógica: estudo exploratório sobre contribuições do PIBID. Projeto Observatório da Educação UECE - UFOP - UNIFESP. CAPES, 2012. (Mimeo).

FARIAS, I. M. S.; JARDILINO, J. R. L.; SILVESTRE, M. A. Aprender a ser professor: aportes de pesquisa sobre o PIBID. Jundiaí: Paco Editora, 2015.

FARIAS, I. M. S. DE; JARDILINO, J. R. L.; SILVESTRE, M. A. Pesquisa em rede e a formação do pesquisador em educação: uma experiência do Observatório da Educação (Obeduc) UECE/UFOP/UNIFESP. Formação Docente Revista Brasileira de Pesquisa sobre Formação de Professores. Belo Horizonte, v. 9, n. 16, p. 109-122, jan./jun. 2017.

GARCÍA, C. M. Formação de professores para uma mudança educativa. Cidade do Porto: Porto Editora, 1999.
GOMES, V. A. F. M.; NUNES, C. M. F.; PÁDUA, K. C.; Condições de trabalho e valorização docente: um diálogo com professoras do ensino fundamental. Revista brasileira de estudos pedagógicos RBEP-INEP, v. 100, p. 277-296, 2019. Disponível em: http://rbep.inep.gov.br/ojs3/index.php/rbep/arti cle/view/3733. Acesso em: 22 jul. 2020. DOl: 10.24109/2176-6681.rbep.100i255.4146

JARDILINO, J. R. L. et al. Contornos de um campo de pesquisa: considerações a partir da produção sobre formação de professores divulgada no GT 08 da ANPEd, 2000-2010. In: REUNIÃO ANUAL DA ANPED, 34., Natal, 2011. Anais da Reunião Anual da Anped. Natal: ANPEd, 2011.

JARDILINO, J. R. L.; OLIVERI, A.M.R. A formação continuada de professores no âmbito do PIBID na Região dos Inconfidentes - MG. EntreVer, Florianópolis, v. 3, n. 4, p. 237-249, jan./jun. 2013.

JARDILINO, J. R. L.; FARIAS, I. M. S. ; OLIVERI, A. M. R. Desenvolvimento Profissional de professores da educação básica nos planos municipais de Educação: Um caso na Região dos Inconfidentes, MG. Revista Educação e Cultura Contemporânea (Online), v. 13, p. 161-180, 2016. Disponível em: http://periodicos.estacio.br/index.php/reeduc/ar ticle/view/2425/1935. Acesso em: 20 jul. 2020. DOI: $10.5935 / 2238-1279.20160066$

JARDILINO, J. R. L.; PEDRUZZI, J. S. A Escola Normal de Ouro Preto: um percurso marcado por crises e reestruturações (1835-1852). Cadernos de História da Educação, v. 15, n. 2, p. 679-699, 2016. Disponível em: Acesso em: 02 ago. 2020.

JARDILINO, J. R. L.; DINIZ, M. Formação de mulheres professoras afrodescendentes: condição e profissão docente na Região dos Inconfidentes.

Revista Historia de Educacion Latinoamericana, v. 18, n. 27, jul./dez., p. 95-114, 2016. Disponível em:

https://revistas.uptc.edu.co/index.php/historia e ducacion latinamerican/article/view/5510.

Acesso em: 25 jul. 2020. DOl: $\underline{10.19053 / 01227238.5510}$

JARDILINO, J.R.L; OLIVERI, A. M. R.; SILVA, I. M. $M$. Desenvolvimento profissional e Inovação 
Pedagógica: A experiências de formação dos professores supervisores do PIBIS na Região dos Inconfidentes, MG. Revista Crítica Educativa, v. 3, p. 78-93, 2017. Disponível em: https://www.criticaeducativa.ufscar.br/index.php /criticaeducativa/article/view/211. Acesso em: 05 ago. 2020. DOI: 10.22476/revcted.v3i2.211

JARDILINO, J. R. L.; SAMPAIO, A. M. M. O Desenvolvimento Profissional Docente e o PNE (2014-2024). InterSaberes: Revista Científica, v. 13, p. 175-183, 2018. Disponível em: https://www.uninter.com/intersaberes/index.ph $\mathrm{p} / \mathrm{revista} / \mathrm{article} / \mathrm{view} / 1381$. Acesso em: 03 ago. 2020. DOI: 10.22169/revint.v13i28.1381

JARDILINO, J.R.L.; SAMPAIO, A. M. M. Demandas de valorização na perspectiva do Desenvolvimento Profissional Docente: Relatos de professores da Educação Básica. Jornal de Políticas Educacionais, v. 12, p. 1-18, 2018. Disponível em: https://revistas.ufpr.br/jpe/article/view/59567.

Acesso em: 03 ago. 2020 DOl: 10.5380/jpe.v12i0.59567

JARDILINO, J. R. L.; DINIZ, M. Universidade e Escola Básica: experiências de pesquisa colaborativa na formação continuada de professores/as. Acta Scientiarum, v. 41. Jan. Dez., p. 1-13, 2019. Disponível em: http://periodicos.uem.br/ojs/index.php/ActaSciE duc/article/view/41958. Acesso em: 27 jul. 2020. DOI: 10.4025/actascieduc.v41i1.41958

JARDILINO, J. R. L; SAMPAIO, A. M. M. Desenvolvimento Profissional Docente: Reflexões sobre política pública de Formação de Professores. Revista Educação e Formação, v. 4, p. 180-194, 2019. Disponível em: https://revistas.uece.br/index.php/redufor/articl e/view/848. Acesso em: 04 ago. 2020. https://doi.org/10.25053/redufor.v4i10.848

JARDILINO, J. R. L.; ARAÚJO., R. B. Desenvolvimento profissional docente e inovação pedagógica: a formação de professores na Região dos Inconfidentes: OBEDUC e PIBID. 1. ed. Curitiba: Editora CRV, 2019. v. 1. 196p.

JARDILINO, J. R. L.; DINIZ, M. Universidade e a Escola Pública: Experiências de pesquisas colaborativas na formação de professores(as). Curitiba: Editora Appris, 2020. 203 p.
JARDILINO, J. R. L; SAMPAIO, A. M. M. O Desenvolvimento Profissional Docente e a Expansão e Estratificação do Sistema Educacional Brasileiro. Revista Educação, Santa Maria, 2020 (no prelo).

LÜDKE, M. (coord). O professor e a pesquisa. Campinas, São Paulo: Papirus, 2004. 3.ed.

MATHIAS, B. H.; JARDILINO, J. R. L. Políticas Públicas e seus ciclos na área educacional: o caso do Ensino de Música. Cadernos de Pósgraduação, v. 18, p. 49-62, 2019. Disponível em: https://periodicos.uninove.br/cadernosdepos/art icle/view/15862. Acesso em: 21 jul. 2020. DOl: 10.5585/cpg.v18n2.15862

MIZUKAMI, M. G. N. M. Relações universidadeescola e aprendizagem da docência: algumas lições de parcerias colaborativas. In: BARBOSA, R. L. L. (org.). Trajetórias e perspectivas de formação de educadores. São Paulo: Editora UNESP, 2004. p. 285-314.

NÓVOA, A. Formação de professores e profissão docente. In: NÓVOA, A. Os professores e a sua formação. 2. ed. Lisboa: Publicações Dom Quixote, 1995. p. 16-33.

NUNES, C. M. F. et al. Formação de professores: investigando programas de desenvolvimento profissional docente nos institutos federais. Crítica Educativa, Sorocaba, v. 5, p. 224-235, 2019.

PEDRUZZI, J. S. A Escola Normal de Ouro Preto: instituição e formação docente no contexto educacional mineiro do século XIX. 2016. 168 f. Dissertação (Mestrado em Educação) Universidade Federal de Ouro Preto, Ouro Preto, 2016.

REALI, A. M. M. Universidade e escola: limites e possibilidades de práticas de colaboração na formação continuada de professores. In: BARBOSA, R. L. L. (org.). Trajetórias e perspectivas de formação de educadores. São Paulo: Editora UNESP, 2004.p.315-328.

ROMANOWSKI, J. P. Apontamentos em pesquisas sobre formação de professores: contribuições para o debate. Rev. Diálogo Educ., Curitiba, v. 12, n. 37, p. 905-924, set./dez. 2012. 
Disponível

em:

https://periodicos.pucpr.br/index.php/dialogoed

ucacional/article/view/4810. Acesso em: 29 jul.2020 DOI: $10.7213 /$ rde.v12i37.4810

SILVA, F. A. O. R.; OLIVEIRA, I. L.; CARVALHO, R. A. Escolhas, vivências e circunstâncias no memorial de formação de professores de Matemática. Revista Brasileira de Pesquisa (Auto)biográfica, v.04, p. 196-214, 2019. Disponível em: https://revistas.uneb.br/index.php/rbpab/article/ view/5728. Acesso em: 29 jul. 2020. DOI: 10.31892/rbpab2525-426X.2019.v04.n10.p196-

$\underline{214}$

TANURI, L. M. História da Formação de Professores. Rev. Bras. Educ., n. 14, p. 61 88,mai./jun./ago. 2000.

VILLELA, H. de O. S. A primeira escola normal do Brasil: uma contribuição à história da formação de professores. 1990. Dissertação (Mestrado em Educação) - Faculdade de Educação da Universidade Federal Fluminense, Universidade Federal Fluminense, Niterói, 1990.

ZEICHNER, K. Novos caminhos para o practicum: uma perspectiva para os anos 90. In: NÓVOA, A. (org.). Os professores e a sua formação. 2. ed. Lisboa: Publicações Dom Quixote, 1995. p. 115138. 